\title{
Consumer Choice of Drinks in Acompetitive Market: Game Theory Approach
}

\author{
Orumie, UkamakaCynthia
}

\begin{abstract}
This research applies the concept of game theory under optimizationtechniques to determine the behavioural factor that affects the choice of soft drinks of residence of Port Harcourt city, Nigeria using its different market strategies. It summarised how best to use marketing strategies to analyse the desirabilityand sales of beverage known as soft drink, using responses from the distributed questionnaires to the residence of PortHarcourt, Nigeria.A case study of Coca-Cola Group of Companies and Seven-up bottling Company were examined and analysed. The payoff matrix was calculated from the harvested data from the distributed questionnaire in eight major populated areasin port Harcourt (University of Port Harcourt, Rivers State University of Science and Technology, ElechiAmadiPolytechnique, Rivers State polytechnic Bori, Fedral College of Education and Technical, Omoku, Mile one market, Mile2 market and Oil mill market, and its environs in Rivers State.) as shown in appendix. The gameresulted to aTwo-person zero sum game which utilised the concept of theminimax-maximin principle, and was analysed using Tora 2013. The result shows that residents of PortHarcourt prefer Coca cola to seven up due to promo, and also Seven up company incurred less loss due to its drink flavour.
\end{abstract}

Keyword: Optimization, marketing strategies, Two-person zero sum game pay off matrix questionnaire, minimax principle

\section{Introduction}

Therehave been different setback and obstacles that one has to address in order to figure out theirlevel of survival since the evolution of man on earth; contending with other species or their kind for land, territory, food.

Today, the rate of competition among organization of different kind is high that the companies are often faced with decision to make in order to increase theirsales that are of great competition with other product in the market. This implies that if companies want to succeed in their targets, they need to continuously check the behaviour attitude of consumers and their priorities due to the fact that consumers are the kings in the business world. Today soft drink has become a vital daily usage which is unavoidable by many user.

Game theory is the study of mathematical models of conflict and co-operation between intelligent rational decisions makers in which each players strategy depends on what the other players does. It is applied in competitive situations and is concerned with interdependent decision in which the options being evaluated are functions of the player's choice.

Gametheory was initially introduced by Von Neumann and Morgenstern (1944) and modified by Nash in 1950 where he demonstrated that for every finite games, there exist an equilibrium point at which all players choose strategy that they consider best for them given their opponents' choices.Every game requires players and a game must consist of at least two players. When the game consists of two players only is called a TWOPERSON GAME, whereas the one that consists of more than two players is called N-PERSON GAME.

Several authors have worked on both game theory and its applications from 1950s till date.

However, Game theory can be applied in the business world such as in a soft drink industry, where two companies (Coca-Cola group of companies, and Seven up,) contend for dominance in the market over the years. These brands have been striving to totally chase the other out of the market or control a large portion of the market. The companies wants to win over existing customers and do not lose them to their competitors. In view of this, over time, different strategies have been employed by the competitors which include advertisement, promo, brand development and branding, as well as cost,and taste. These strategies will determine the company which will dominates in the market.

However, the research wants to apply the concept of the two-person zero-sum game theory to determine what strategy will be of benefit to the individual companies in order to win in the market.

In section two, brief explanation of two person zero sum game will be provided, followed by the history of the two beverage companies in section three.Data collection, analyses and computational result will be presented in section four and five respectively.Section six and seven includes summary of result and conclusion respectively. 


\section{Two Person Zero Sum Game}

Game which requires only two players is called Two-Person Game. In a Two-Person game, when one player wins, it implies a direct and equal loss to the other player. This is called Zero -Sum Game.This involves list of possible course of actions that can be taken by a player called STRATEGIES which are chosen by a player in order to either minimizes his loss or maximizes his gain. The particular combination of strategies that best does this to both party is referred to as optimal strategy. As a result of picking a particular strategy, a player derives a degree of satisfaction called PAYOFF.

Therefore a player will obtain maximum payoff if he selects his optimal strategy. Game theory provides a data structure called PAYOFF MATRIX which is used to calculate the VALUE OF THE GAME. i.e the value that represents the maximum payoff for each player. It can also be the expected outcome when two players choose their optimal strategies. In a pure strategy game, the saddle point is the value of the game while a mixed strategy game, the value of the game is solved by choosing from strategies with fixed probabilities. The value of the game satisfy the following:Maximum value $\leq \mathrm{v} \leq$ minimum value, where $\mathrm{v}$ is the value of the game.

Generally, assumptions of this type of game are;

- Each players has available to him a finite number of possible strategies

- Players act rationally and intelligently

- One player attempt to maximize gain and the other attempt to minimize loss

- Both players make their decision individually, prior to the play, without direct communication between them.

- The payoff is fixed and determined in advance.

\section{Data Base And Historical Background Of The Companies}

Literature recorded that Coca-Cola was initially discoveredby John P. in 1886 ; an American scientist during his quest for a quick relief of headaches and tiredness. It was a combination of carbonated water and tested on a selected number of persons who accepted to be used.He sold the company to an Atlanta man known and addressed as Griggs Candler in 1891. Candler became the first company's president who brought the vision to the business and the brand. He changed Coca-Cola from an invention into a business.

In 1895, He built syrup plant in Chicago, Dallas and Los Angeles.Coca-Colacame to Nigeria In 1951, and in that same year, the Nigerian bottling company (NBC) was incorporated to bottle and sell the carbonated non-alcoholic beverage. Normal production started in 1953 at Lagos State and in the same year, the first bottling plant was opened in Apapa, Lagos State. Today, the company has different products in many countries and thousands of plants and factories across the world.

Seven-up was invented in 1920 by Charles Grigg. In 1929, he came up with the formula for a lemonlime sod now known as Seven-up (7up). The name of the company was changed from Howdy Corporated to the Seven-up Company in 1940.

In 1960, the country experienced the birth of seven up in Yora, Lagos State. Today, the company has grown into a class beverage with factories all over the world.

\subsection{Data Collection/Presentation}

This research employed primary data. This was obtained through distributions of questionnaires as shown in appendix A to residence of Port Harcourt. A simple random sampling technique called the table of random number was employed to determine eight major populated areas to be covered which gave, University of Port Harcourt, Rivers StateUniversity of Science and Technology, ElechiAmadiPolytechnique, Rivers State polytechnic Bori, FedralCollege of Education and Technical, Omoku, Mile one market, Mile2 market and Oil mill market, and its environs in Rivers State. A total of twenty five thousand $(25,000)$ questionnaires were distributed out of which only ten thousand five hundred and ninety two $(10,592)$ respondentscomplied as presented in tables below.

The two major beverage companies in Nigeria, Coca-cola Group of Companies (which produces sprite, coke and Fanta) and Seven-up Bottling Company (which produces pepsi, mirinda and seven-up) are the players and the factors considered in the questionnaire are:
i. Advertisement (ADV)
ii. Promos (PRO)
iii. Packaging (PAC)
iv. Sugar level (S/L)
v. Flavour (FL)
vi. Prize $(\mathrm{P})$
vii. Taste(T) 
Data collated by the researcher were fully utilized to ensure that the purpose of the statistical input is not biased.

The table3.1 below shows the number of respondents that prefers a particular drink to the other considering different factors. Also factors that affect movement of customers from one brand to the other, the rate of movement from one brand to another, and as well as customers who stayed loyal to their brand based on certain factors are also tabulated.

Table 3.1: Table of Factors against Movement

\begin{tabular}{|l|l|l|l|l|}
\hline BRAND & FACTORS & COCA & SEVEN UP & RETAINED CUSTOMERS \\
\hline Coca & Advert & - & 356 & 158 \\
\cline { 2 - 5 } & Promo & - & 210 & 163 \\
\cline { 2 - 5 } & Pack & - & 192 & 147 \\
\cline { 2 - 5 } & Sugar & - & 326 & 167 \\
\cline { 2 - 5 } & Flavor & - & 415 & 142 \\
\cline { 2 - 5 } & Prize & - & 399 & 140 \\
\cline { 2 - 5 } & Taste & - & 400 & 112 \\
\hline \multirow{5}{*}{ Ueven } & Advert & 820 & - & 100 \\
\cline { 2 - 5 } & Promo & 918 & - & 109 \\
\cline { 2 - 5 } & Pack & 752 & - & 122 \\
\cline { 2 - 5 } & Sugar Level & 608 & -- & 132 \\
\cline { 2 - 5 } & Flavour & 667 & - & 140 \\
\cline { 2 - 5 } & Prize & 723 & - & \\
\cline { 2 - 5 } & Taste & 605 & - & \multicolumn{1}{|c}{} \\
\hline
\end{tabular}

Source: own research (generated from questionnaire from the field)

Based on the above result, the payoff matrix of two competitors say A and B at a time for any given pair of strategies will be determined. This is done by comparing the payoff for one competitor A using a particular strategy against the other B, using his own strategy.

Mathematically, let A be gaining competitor(Coca-Cola) be represented by rows on the payoff matrix with strategies ( $\alpha \mathrm{i}: \mathrm{i}=1,2, \ldots \mathrm{n}$ ) having payoffs ( $\mathrm{a}, \mathrm{b}, \mathrm{c}, \mathrm{d}, \mathrm{e}, \mathrm{f}, \mathrm{g}$ ) and $\mathrm{B}$ be a losing competitor(seven up company) represented by columns on the payoff matrix with strategies $\left(\beta_{1}: i=1,2, \ldots n\right)$ having payoffs $(h, i, j, k, 1, m, n)$. Let $r_{i}: i=1,2, \ldots 7$ be the number of customers retained by A (COCA COLA) company due to factors $\alpha_{i}$, and $v_{i}$; $\mathrm{i}=1,2, \ldots 7$ be the number of customers retained by $\mathrm{b}$ (Seven up) company due to factors $\beta_{\mathrm{i}}$ respectively, then the Table of Factors against Movement becomes

Table 3.2: Table of Factors against Movement

\begin{tabular}{|l|l|l|l|l|}
\hline BRAND & FACTORS & COCA & SEVEN UP & RETAINED CUSTOMERS \\
\hline \multirow{5}{*}{ Coca } & Advert & & $356=\mathrm{h}$ & $158=\mathrm{r}$ \\
\cline { 2 - 5 } & Promo & & $210=\mathrm{i}$ & $163=\mathrm{r} 2$ \\
\cline { 2 - 5 } & Pack & & $192=\mathrm{j}$ & $147=3$ \\
\cline { 2 - 5 } & Sugar & & $326=\mathrm{k}$ & $167=\mathrm{r} 4$ \\
\cline { 2 - 5 } & Flavor & & $415=\mathrm{L}$ & $142=\mathrm{r} 5$ \\
\cline { 2 - 5 } & Prize & & $399=\mathrm{M}$ & $140=\mathrm{r} 7$ \\
\cline { 2 - 5 } & Taste & $820=\mathrm{a}$ & & $112=\mathrm{V} 1$ \\
\hline \multirow{5}{*}{ Seven Up } & Advert & $918=\mathrm{b}$ & & $100=\mathrm{V} 2$ \\
\cline { 2 - 5 } & Promo & $752=\mathrm{c}$ & & $109=\mathrm{v} 3$ \\
\cline { 2 - 5 } & Pack & $608=\mathrm{d}$ & & $122=\mathrm{V} 4$ \\
\cline { 2 - 5 } & Sugar Level & $667=\mathrm{e}$ & & $131=\mathrm{V} 5$ \\
\cline { 2 - 5 } & Flavour & $723=\mathrm{f}$ & & $140=\mathrm{V} 7$ \\
\cline { 2 - 5 } & Prize & $605=\mathrm{g}$ & & \\
\cline { 2 - 5 } & Taste & & \\
\hline
\end{tabular}

Source: own research (generated from questionnaire from the field)

And the resulting $7 * 7$ value of the payoff table will be calculated thus ;

Table 3.3: Payoff tablecalculation

\begin{tabular}{|c|c|c|c|c|c|c|}
\hline $\begin{array}{l}\mathrm{a}_{11}=\alpha_{1}- \\
\beta_{1,=(\mathrm{a}+\mathrm{r} 1)-} \\
(\mathrm{h}+\mathrm{V} 1)=(820+1 \\
58)-(356+112)\end{array}$ & $\begin{array}{l}a_{12}=\alpha_{1}-\beta_{2} \\
=(a+r 1) \\
(i+v 2)=(=210+15 \\
8)-(210+100)\end{array}$ & $\begin{array}{l}a_{13}=\alpha_{1}-\beta_{3} \\
=(a+r 1)-(j+V 3) \\
=(820+158-)- \\
(192+109)\end{array}$ & $\begin{array}{l}\text { a14 }=\alpha_{1}- \\
\beta_{4} \\
=(\mathrm{a}+\mathrm{r} 1)- \\
(\mathrm{k}+\mathrm{v} 4) \\
=(820+158)- \\
(326+122)\end{array}$ & $\begin{array}{l}\mathrm{a} 15=\alpha_{1}- \\
\beta_{5,} \\
=(\mathrm{a}+\mathrm{r} 1)- \\
(\mathrm{L}+\mathrm{v} 5 \\
=(978)- \\
(415+141)\end{array}$ & $\begin{array}{l}a_{16}=\alpha_{1}-\beta_{6} \\
=(a+r 1)- \\
(m+v 6)- \\
(978)- \\
(399+132)\end{array}$ & $\begin{array}{l}a_{17}=\alpha_{1}-\beta_{7}, \\
=(a+r 1)- \\
(n+v 7)=(978)- \\
(540)=\end{array}$ \\
\hline $\begin{array}{l}a_{21}=\alpha_{2}-\beta_{1} \\
=(b+r 2)-(h+v 1)\end{array}$ & $\begin{array}{l}a_{22}=\alpha_{2}-\beta_{2} \\
=(b+r 2)-(i+v 2) \\
=(918+163)\end{array}$ & $\begin{array}{l}a_{23}=\alpha_{2}-\beta_{3} \\
=(b+r 2)- \\
(j+v 3)=(918+16\end{array}$ & $\begin{array}{l}a_{24}=\alpha_{2}-\beta_{4} \\
=(b+r 2)- \\
(k+v 4)\end{array}$ & $\begin{array}{l}a_{25}=\alpha_{2}- \\
\beta_{5} \\
=(b+r 2)-\end{array}$ & $\begin{array}{l}\mathrm{a}_{26}=\alpha_{2}-\beta_{6} \\
=(\mathrm{b}+\mathrm{r} 2)- \\
(\mathrm{m}+\mathrm{v} 6)-\end{array}$ & $\begin{array}{l}a_{27}=\alpha_{2}-\beta_{7} \\
=(b+r 2)- \\
(n+v 7)\end{array}$ \\
\hline
\end{tabular}


Consumer Choice of Drinks in Acompetitive Market: Game Theory Approach

\begin{tabular}{|c|c|c|c|c|c|c|}
\hline $\begin{array}{l}=(918+163)- \\
(356+112)\end{array}$ & $-(210+100)$ & 3)-(192+109) & $\begin{array}{l}=(918+163)- \\
(326+122)\end{array}$ & $\begin{array}{l}(M+v 6)=(1 \\
081)- \\
(415+141)\end{array}$ & $\begin{array}{l}=(1081)- \\
(399+132)\end{array}$ & $\begin{array}{l}=(\mathrm{r} 2)-\mathrm{n}+\mathrm{v} 7) \\
=(1081)-(540)\end{array}$ \\
\hline $\begin{array}{l}a_{31}=\alpha_{3}-\beta_{1,} \\
=(C+r 3)-(h+v 1) \\
=(752+147)- \\
(356+112)\end{array}$ & $\begin{array}{l}\mathrm{a}_{32}=\alpha_{3}-\beta_{2} \\
=(\mathrm{c}+\mathrm{r} 3)-(\mathrm{i}+\mathrm{v} 2) \\
=(752+147) \\
-(210+100)\end{array}$ & $\begin{array}{l}a_{33}=\alpha_{3}-\beta_{3} \\
=(c+r 3)- \\
(j+v 3)=(752+14 \\
7)-(192+109)\end{array}$ & $\begin{array}{l}a_{34}=\alpha_{3}- \\
\beta_{4}=(c+r 3)- \\
(k+v 4) \\
=(752+147)- \\
(326+122)\end{array}$ & $\begin{array}{l}a_{35}=\alpha_{3}- \\
\beta_{5}=(c+r 3)- \\
l+v 5)=(899 \\
)- \\
(415+141)\end{array}$ & $\begin{array}{l}a_{36}=\alpha_{3}- \\
\beta_{6}=(c+r 3)- \\
(m+v 6) \\
=(899)- \\
(399+132)\end{array}$ & $\begin{array}{l}a_{37}=\alpha_{3}-\beta_{7} \\
=(c+r 3)- \\
(n+v 7) \\
=(899)-(540)\end{array}$ \\
\hline $\begin{array}{l}a_{41}=\alpha_{4}-\beta_{1} \\
=(d+r 4)-(h+v 1) \\
=(608+167)- \\
(356+112)\end{array}$ & $\begin{array}{l}\mathrm{a}_{42}=\alpha_{4}-\beta_{2} \\
=(\mathrm{d}+\mathrm{r} 4)-(\mathrm{i}+\mathrm{V} 2) \\
=(608+167) \\
-(210+100)\end{array}$ & $\begin{array}{l}a_{43}=\alpha_{4}-\beta_{3} \\
=(d+r 4)(j+v 3) \\
=(608+167)- \\
(192+109)\end{array}$ & $\begin{array}{l}a_{44}=\alpha_{4}- \\
\beta_{4}=(d+r 4)- \\
(k+v 4) \\
=(608+167)- \\
(326+122)\end{array}$ & $\begin{array}{l}a_{45}=\alpha_{4}- \\
\beta_{5}=(d+r 4)- \\
(1+v 5) \\
=(775)- \\
(415+141)\end{array}$ & $\begin{array}{l}a_{46}=\alpha_{4}- \\
\beta_{6}=(d+r 4)- \\
(m+v 6)- \\
(775)- \\
(399+132)\end{array}$ & $\begin{array}{l}a_{47}=\alpha_{4}-\beta_{7} \\
=(d+r 4)- \\
(n+v 7) \\
=(775)-(540)\end{array}$ \\
\hline $\begin{array}{l}a_{51}=\alpha_{5}-\beta_{1} \\
=(e+r 5)(h+v 1) \\
=(667+142)- \\
(356+112)\end{array}$ & $\begin{array}{l}a_{52}=\alpha_{5}-\beta_{2} \\
=(f+r 6)-(i+v 2) \\
=(667+142) \\
-(210+100)\end{array}$ & $\begin{array}{l}a_{53}=\alpha_{5}-\beta_{3} \\
=(f+r 5)-(j+v 3) \\
=(667+142)- \\
(192+109)\end{array}$ & $\begin{array}{l}\mathrm{a}_{54}=\alpha_{5}-\beta_{4} \\
=(\mathrm{e}+\mathrm{r} 5)- \\
(\mathrm{k}+\mathrm{v} 4) \\
=(667+142)- \\
(326+122)\end{array}$ & $\begin{array}{l}a_{55}=\alpha_{5}- \\
\beta_{5} \\
=(e+r 5)- \\
(1+\mathrm{V} 5) \\
=(809)- \\
(415+141)\end{array}$ & $\begin{array}{l}a_{56}=\alpha_{5}-\beta_{6} \\
=(e+r 5)- \\
(M+v 6) \\
=(809)- \\
(399+132)\end{array}$ & $\begin{array}{l}a_{57}=\alpha_{5}-\beta_{7} \\
=(e+r 5)- \\
(n+v 7) \\
=(809)-(540)\end{array}$ \\
\hline $\begin{array}{l}a_{61}=\alpha_{6}-\beta_{1} \\
=(f+r 6)-(h+v 1) \\
=(723+152)- \\
(356+112)\end{array}$ & $\begin{array}{l}a_{62}=\alpha_{6}-\beta_{2} \\
=(g+r 7)- \\
(i+v 2)=(723152)- \\
(2010+100)\end{array}$ & $\begin{array}{l}a_{63}=\alpha_{6}-\beta_{3} \\
=(f+r 6)-(j+v 3) \\
=(723+152)- \\
(192+109)\end{array}$ & $\begin{array}{l}\mathrm{a}_{64}=\alpha_{6}-\beta_{4} \\
=(\mathrm{f}=\mathrm{r} 6-)- \\
(\mathrm{k}+\mathrm{v} 4) \\
=(723+152)- \\
(326+122)\end{array}$ & $\begin{array}{l}a_{65}=\alpha_{6} \beta_{5} \\
=(f=r 6)- \\
(1+v 5) \\
=(875)- \\
(415+141)\end{array}$ & $\begin{array}{l}a_{66}=\alpha_{6}-\beta_{6} \\
=(f+r 6)- \\
(M+V 6)=(87 \\
5)- \\
(399+132)\end{array}$ & $\begin{array}{l}a_{67}=\alpha_{6}-\beta_{7} \\
=(f+r 6)- \\
(n+v 7)=(875)- \\
(540)\end{array}$ \\
\hline $\begin{array}{l}a_{71}=\alpha_{7}-\beta_{1} \\
=(g+r 7) \\
(h+v 1) \\
=(605+140)- \\
356+112)\end{array}$ & $\begin{array}{l}a_{72}=\alpha_{7}-\beta_{2} \\
=(g+r 3)-(i+v 2) \\
=(605+140)- \\
(210+100)\end{array}$ & $\begin{array}{l}a_{73}=\alpha_{7}-\beta_{3} \\
=(g+r 7)-(j+v 3) \\
=(605+140)- \\
(192)+109)\end{array}$ & $\begin{array}{l}a_{74}=\alpha_{7}- \\
\beta_{4}=(g+r 7)- \\
(k+v 4) \\
=(605+140)- \\
(326+122)\end{array}$ & $\begin{array}{l}a_{75}=\alpha_{7}- \\
\beta_{5} \\
=(g+r 7)- \\
(l+v 5)- \\
=(745)- \\
(415+141)\end{array}$ & $\begin{array}{l}a_{76}=\alpha_{7}-\beta_{6} \\
=(g=r 7)- \\
(M+v 6) \\
=(745)-399)- \\
(132)\end{array}$ & $\begin{array}{l}\mathrm{a}_{77}=\alpha_{5}-\beta_{7} \\
=(\mathrm{g}+\mathrm{r} 7)- \\
(\mathrm{n}+\mathrm{v} 7) \\
=(745)-(540)\end{array}$ \\
\hline
\end{tabular}

Source: own research (calculated fromtable 3.2)

The above yields the values in the pay off matrix below;

Table 3.4: The pay off matrix of Coca-Cola versus Seven-Up

\begin{tabular}{|c|c|c|c|c|c|c|c|c|}
\hline & \multicolumn{8}{|c|}{ SEVEN UP } \\
\hline \multicolumn{9}{|c|}{ 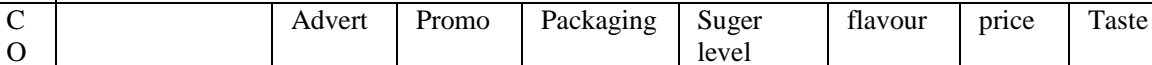 } \\
\hline $\mathrm{C}$ & Advert & 510 & 668 & 677 & 530 & 422 & 447 & 438 \\
\hline A- & Promo & 613 & 771 & 780 & 633 & 525 & 550 & 541 \\
\hline $\mathrm{C}$ & Packaging & 431 & 589 & 598 & 451 & 343 & 368 & 359 \\
\hline $\mathrm{O}$ & Suger level & 307 & 465 & 474 & 327 & 219 & 244 & 235 \\
\hline L & flavour & 341 & 499 & 508 & 361 & 253 & 278 & 369 \\
\hline A & price & 407 & 565 & 574 & 427 & 319 & 344 & 335 \\
\hline & Taste & 277 & 435 & 444 & 297 & 189 & 214 & 205 \\
\hline
\end{tabular}

Source: own research (generated from table 3.3)

\section{Theory And Methods}

Apply the rule of game as shown below to table 3.4:

RULES FOR GAME THEORY

- A two person zero sum game in strategic(or normal form) $\alpha$ and $\beta$ consist of two strategy set

- A play of the game consists of player A choosing a strategy $\alpha_{i} \in \alpha$ and player B simultaneously choosing a strategy $\beta_{j} \in \beta$. Player $\mathrm{A}$ is then awarded $\mathrm{A}\left(\alpha_{i}, \beta_{j}\right)$ in winning and player $\mathrm{A}$ awarded $-\mathrm{A}\left(\alpha_{i}, \beta_{j}\right)$

- Look for a pure strategy or saddle point $(\operatorname{minmax}=\operatorname{maximin}=$ game $)$. It is the point of equilibrium

- If $\mathrm{v}=0$ then the game is said to be fair

- If $\mathrm{v}>0$ then the game is favourable to player along row a

- If $\mathrm{v}<0$ it is favourable to the player along the column 
If there is no saddle point (it is not pure but mixed) then we apply the rule of dominance which state

- Delete the columns that is less than or equal to any other column

- Delete the row that is less than or equal to the next

- Then solve by mathematical method

Then, inputing the above values intora gives table 4.1 below

Table 4.1: INPUT TABLE

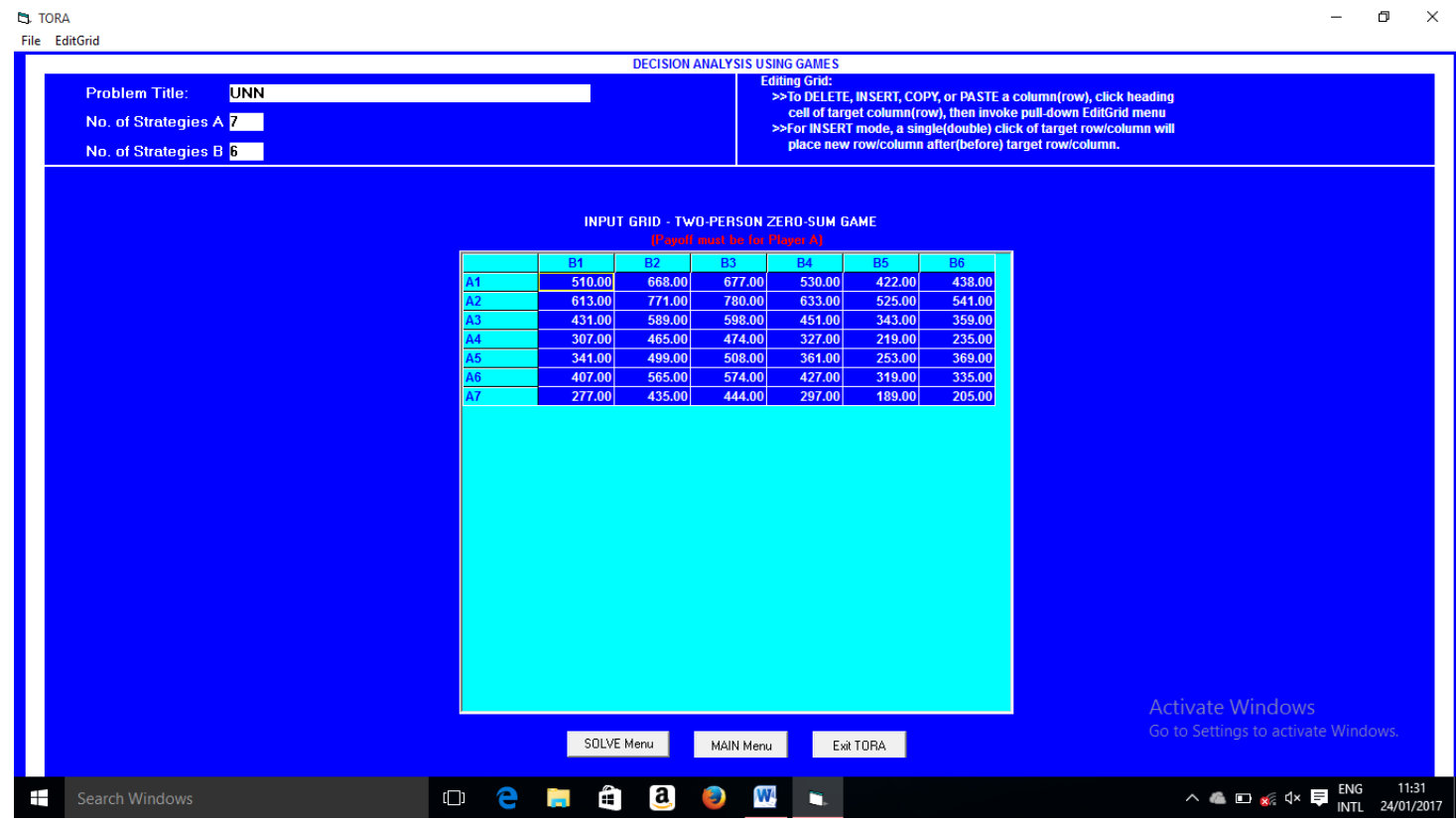

And the output is;

Table 4.2 Out Put Result Table

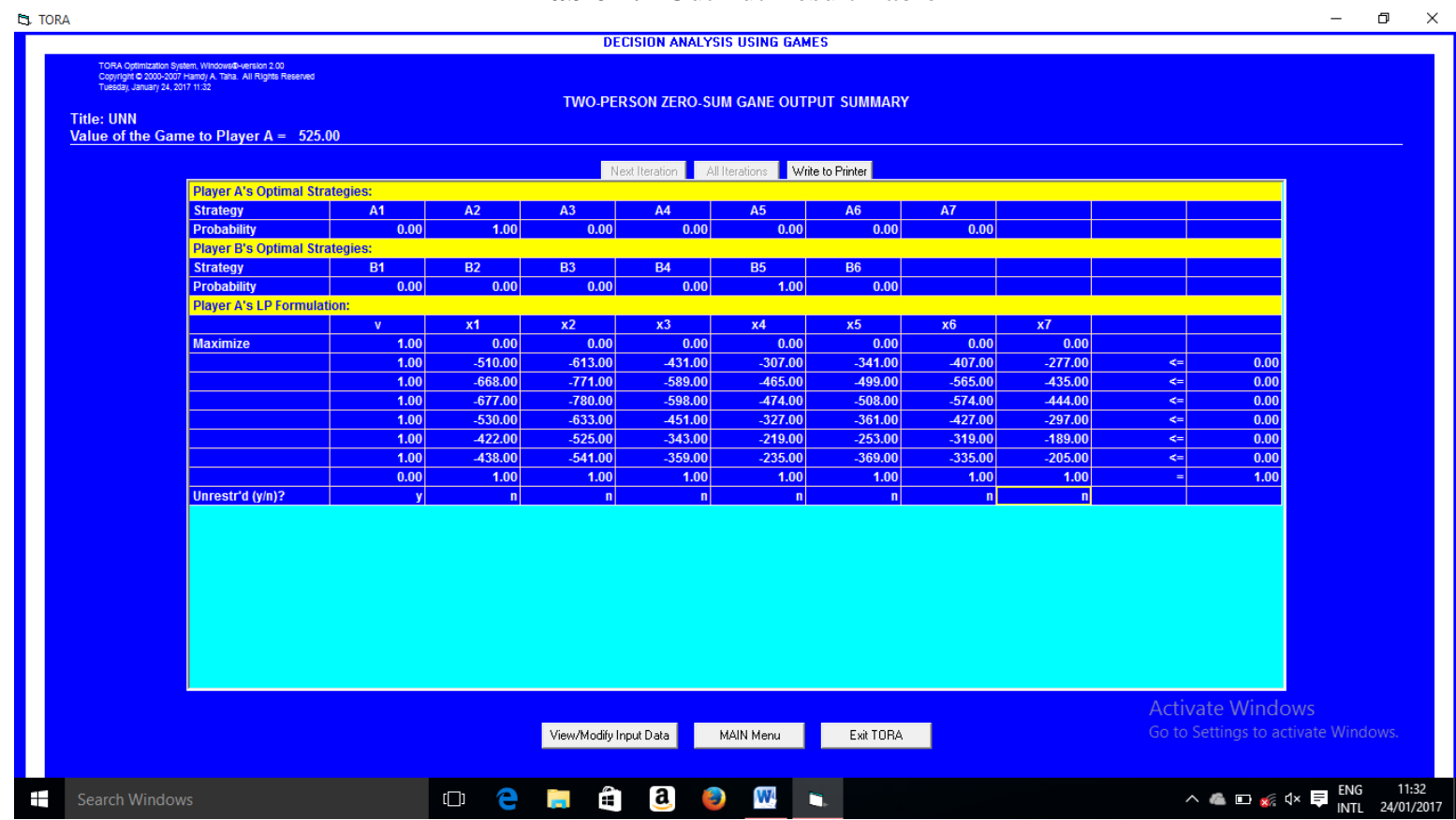

\section{Results}

Minimax- maximin principle together with Tora 2006 were used to analyze the data in the cost matrix on table 3.4 and 4.1, the result obtained shows thatthe table has a saddle point at (Promo, flavour) at the $\operatorname{minimax}$ value $=525=$ maximin value. Hence the value of the game is 525 . This shows that the game is favorable to Coca-Cola (coke). 
It implies that the resident of PortHarcourt City prefers coke than Sevenup in terms of promo. That is to say that Coca-Cola has an advantage of promo over seven-up as it brings gain to them irrespective of SevenUp's course of action, while the factor 'flavour' brings less loss to Seven-Up.

The result of this research shows that the competition between the beverage companies is a pure strategy game.

\section{Summary And Conclusion}

It was observed from the data collected, that the companies' factors greatly affect the market flow of the two soft drinks companies. This influences the decision of the customers as to what brand to choose and if already drinking a brand, to remain with the brand or to move to the other brand.

From the analysis, it is noticed that Coca-Cola Company's promo brings them more customers and/or make their existing customers to remain with the brand; thus enhancing companies profit. This is due to the fact that more customers buy more of coca cola product when compared with that of seven up. However, because of the flavour of Seven-Up, the probability of them losing their customer is obvious.

\section{Recommendations}

It is observed that the strength of Coca-Cola is their promo. But this does not necessarily mean that it is the only available strategy; hence, Coca-Cola while retaining their promos strategy, should also improve on their flavour in other to be in total control. Also, Seven-Up, while capitalizing on their flavour, should improve on advertisement and promos.

In general, it has been shown from this research that one strategy is not enough to keep any firm in business; hence, other factors that cause the movement of customers should be considered and improved upon to a satisfactory level.

\section{References}

[1] Ekanem O. T, Iyoha M.A (2000). Mathematical Economic: An Introduction. Benin City: Mareh Publishers.

[2] Jingjing Liu and YuqiZou(2013) game theory based research on profit distribution among stakeholders in urban renewal project.

[3] Mlvin Dresher (1961)Games of Strategy: Theory and Applications, Prentice Hall, Inc. N.J

[4] Carmichael F.: A Guide to Game Theory, Prentice Hall, Yew Jersey, USA, 2005.

[5] Rapoport and Chammah (1966) pp. 10-14 and 23-28. GAME OF CHICKEN

[6] Robert Gibbons.(1997)An Introduction to Applicable Game Theory The Journal of Economic Perspectives, Vol. 11, No. 1. Winter, pp. 127-149.

[7] Sun Lianju and PengLuyan.(2011) Game theory analysis of bribery behavior. International journal

[8] Tucker, A. W. (1958). "John von Neumann's work in the theory of games and mathematical economics". Bull. Amer. Math. Soc. 64 (Part 2) (3): 100-122

[9] Von Neumann, J: (1928). "ZurTheorie der Gesellschaftsspiele". MathematischeAnnalen (in German) 100: $295-320$.

[10] ZHANG Gui-qin, XU Zhi-fei and ZHANG Wei, (2011)Strategy Research on Bidding of Construction Project Based on Game Theory International Conference on Information Management and Engineering

[11] APPENDIX A

[12] Dear respondent, I am Orumie, U.C of Department of mathematic and statistics, UNIPORT. I am carrying out a research on the CONSUMER CHOICE OF DRINK "COCA-COLA AND SEVEN-UP COMPANY"

[13] Please your information on the questions below are highly required, and will be kept confidential. I shall appreciate your cooperation.

[14] INSTRUCTION:Please read the following questions carefully and tick the answer which you feel is appropriate.

\section{Instruction}

Please tick as appropriate and just indicate a number where needed.

\section{Section A}

1. Sex:

Male

2.

Age:

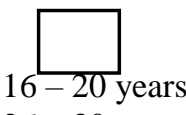

$26-30$ years

$36-40$ years

$46-50$ years

3. Category:

Staff

Student

business

civil servant

self employed
Female

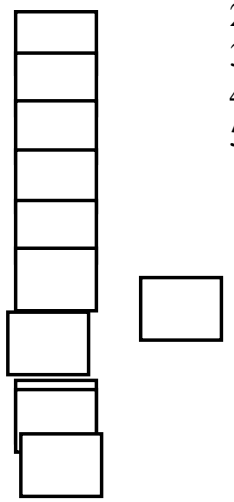

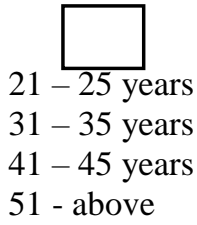
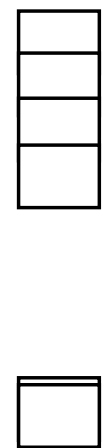


\section{Section B}

1. Which brand do you think has done better in terms of:
Coca-cola
Seven-up

2. Would you lik thange to a better brand?

Yes

3. a) If yes, why?

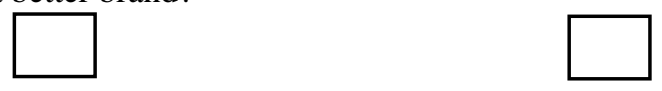

- Advertisement

- Promo

- Packaging

- Sugar level

- Flavour

- Prize

- Taste

b) If no, why?

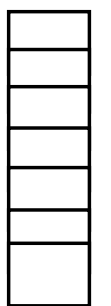

- Advertisement

- Promo

- Packaging

- Sugar level

- Flavour

- Prize

- Taste

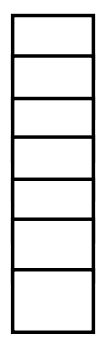

4. When both are available, which do you prefer:

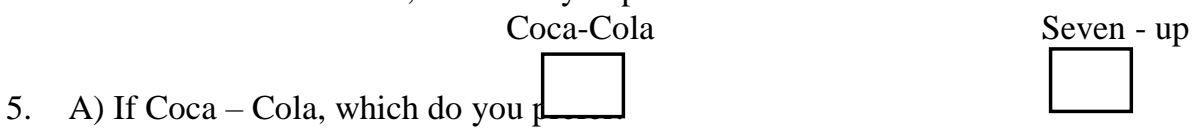
Coke

Fanta

Sprite

B) If seven - up, which do you prefer:

Seven up

Pepsi

Mirinda

6. How long have you been taking your preferred brand?

$$
\begin{aligned}
& 0-5 \text { years } \\
& 11-15 \text { years } \\
& 21-25 \text { years }
\end{aligned}
$$
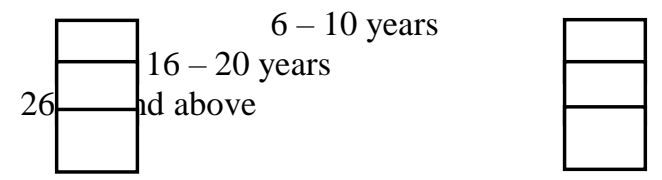